\title{
Our Most Powerful Weapon to Fight COVID-19: Patient Involvement
}

\author{
Peter J. Pitts ${ }^{1,2}$ \\ Published online: 16 April 2020 \\ (c) Springer Nature Switzerland AG 2020
}

The COVID-19 pandemic has catapulted the issue of the patient voice in healthcare and healthcare policy to the front of the global agenda. From social distancing, quarantines, and the wearing of masks, to questions surrounding the urgency of vaccines, hygiene, clinical trials, 'emergency use authorizations', testing, and convalescent plasma, the world has moved beyond general issues such as health literacy to a more crucial issue ... the role of the patient voice in partnering to save our species from a devastating virus though informed and active participation.

Our armamentarium of medical weapons to fight the COVID-19 virus (swifter and more accurate testing, repurposed existing therapeutics and experimental medicines, expedited vaccine development) have received the most attention, but it is the active participation of patients and (more broadly) the general population that has 'flattened the curve'. The pandemic has resulted in an evolution of healthcare rhetoric. From a healthcare policy perspective, we have been discussing 'the patient voice' in a passive manner. An important lesson from the COVID-19 experience is that we must now shift to a more comprehensive understanding of 'patient actions'.

More important than these actions are the myths and facts that drove them. This raises crucial questions. How can truthful, accurate and non-misleading information be made available to non-medical professionals? From whom should it come? What are the best methods of communication? The circumstances surrounding hydrocloroquine $[1,2]$ highlight both the power of hope and the dangers of hyperbole.
As with any ecosystem, the component parts of our healthcare systems are not necessarily equal to each other, but they are all requirements for success. What the patient voice must fight for is equal respect and a recognition of mutual value. It is not a question of 'equal' but of 'integral'.

The global struggle against COVID-19 is World War III and we are all conscripted. Whether you are a physician, nurse, hospital technician, academic researcher, biopharmaceutical executive, police officer, firefighter, teacher, politician, parent, patient, or caregiver, we have a powerful and active role to play. When cities are burning and casualties are mounting, there is no place for casual observers. We must all shoulder our metaphorical rifles and march forward together.

All the more reason to elevate a discussion of the twentyfirst century patient voice in healthcare [3]. In the words of W. Edwards Deming, "Change is not required. Survival is not mandatory". We must not pass up these opportunistic teaching moments.

\section{References}

1. Wilson FP. COVID-19, Hydroxychloroquine, and the Death of Evidence-Based Medicine. https://www.methodsman.com/blog/ covid-19-evidence.

2. Owens B. Excitement around hydroxychloroquine for treating COVID-19 causes challenges for rheumatology. Lancet. 2020. https://doi.org/10.1016/S2665-9913(20)30089-8.

3. Pitts PJ. Towards meaningful engagement for the patient voice. Patient. 2019;12:361-63. https://doi.org/10.1007/s40271-01900366-x.
Peter J. Pitts

ppitts@cmpi.org

1 University of Paris, Paris, France

2 Center for Medicine in the Public Interest, New York, NY, USA 